\title{
Rigorous Reasoning, Reflexive Research and the Space for 'Alternative Archaeologies'. Questions for Maritime Archaeological Heritage Management.
}

\author{
Jesse Ransley \\ University of Southampton, Avenue Campus, Highfield, Southampton, SO17 IUY
}

\begin{abstract}
As England's heritage policy is shaped around us, it is vital that there is debate, and some consensus, among the maritime archaeological community on core management questions. These include approaches to degrading underwater sites, how to deal with shipwrecks threatened by development, and crucially, who should be driving these decisions. This paper argues that there is a need for self-critical analysis of the meaning of 'heritage'. It problematises the notion of professional archaeologists as 'guardians of the archaeological record' and the conception of 'heritage' formed without reference to ideas of the past being a product of the present and, therefore, the potential for the production of multiple pasts.
\end{abstract}

(C) 2007 The Author

Key words: heritage management, professionalisation, the 'archaeological record', ethics, multiple pasts, alternative archaeologies.

$\mathbf{T}$ he 2002 National Heritage Act initiated a massive shift in England's maritime archaeological sphere. With it, English Heritage's remit was extended to include maritime archaeology (the term 'maritime archaeology' will be used throughout for the sake of consistency, but is intended to refer inclusively to all underwater, nautical, coastal and marine archaeology). Before its introduction, there had been no formalised system of heritage management which included the marine historic environment. Rather than the model of a centralised national heritage agency, working alongside county and district curatorial roles, seen terrestrially, maritime archaeology fell beyond legislated curatorial remits, and outside local and national government sources of funding. Consequently, English Heritage's advance into maritime archaeology engendered a wide range of expectations among the academics, charitable trusts, avocational groups and the small number of contractors working in the field. Those expectations and preconceptions of what might or ought to result from these changes, ranged dramatically from the hopeful and pragmatic, to the cynical and sometimes derisive, to in a few cases the wildly unrealistic and ethically and ideologically dubious.
On the one hand some people seemed to be expecting some kind of guard-dog, snarling and protecting maritime archaeological heritage from those miscreants who might destroy or harm it: developers, treasure-hunters, fishermen, divers, and pretty much everyone else. On the other, there seemed to be an expectation that English Heritage would play a fairy-godmother role, granting monetary wishes, so that archaeologists could start getting on with things properly, digging up, investigating and 'doing' maritime archaeology. Nowhere in this fractured discourse was there any reflective examination of the source of these expectations and desires for English maritime archaeology. Neither was there impartial and objective debate of the broader strategy and direction that should be pursued and the difficult issues that would need to be faced; nor analysis of the wider frameworks within which maritime archaeological heritage-management systems would have to fit.

In reality, 2002 saw Ian Oxley, the new Head of Maritime Archaeology at English Heritage, arriving at a new desk in an empty office, with what could be diplomatically termed 'a number of challenging issues and tasks' ahead. In the four-and-a-half years since his appointment there 
have been significant changes, not least in engagement with industries operating in the marine environment, in development consultation, and with regulators and the planning and consents process. Strategic and methodological research projects have been commissioned. There has been support for the development of university courses and training in the sector, changes in the management of designated shipwreck sites, and the raising of awareness within both government and the larger curatorial and heritage-management sector. By necessity much of this has been reactive. And so, as the dust settles, there is now a genuine opportunity to engage in 'impartial and objective' debate about the direction which should be taken in the coming years.

Every move by English Heritage so far has engendered a flurry of opinion and a series of individual soliloquies, both positive and negative, along with the ubiquitous 'rant in the pub'. However, there has not been a concerted effort to examine these issues in a more abstract, less emotive way. With so much personal opinion bandied about, the lack of incisive responses to the recent government maritime heritage protection review consultation is telling (DCMS, 2005). While the similar absence of open and unprejudiced debate about the issues underlying recent cases, such as that of the Elizabethan wreck recovered from Princes Channel in the Thames, is stark. In addition, the singular lack of academic interest in, engagement with, and research into, maritime archaeological heritage management is, at the very least, inopportune and regrettable.

This last point in particular is important. It is becoming apparent, and one of the few things upon which there is clear consensus, that we cannot simply impose terrestrial management models onto marine archaeological problems. The physical environment, site-formation processes, research gaps, agendas, and methodologies, as well as monitoring, access and interpretation logistics, are too markedly different. As a consequence, there needs to be engagement in the development of new, rigorously-reasoned and inclusively-generated policies for our maritime archaeological heritage.

In light of this, this paper will briefly discuss two maritime archaeological heritage-management questions that are increasingly relevant in England and the UK and which require wider debate. Firstly, the question of 'preservation in situ' and the tensions that arise from this, such as that between reburial and public and research access to protected sites, will be examined. Secondly, 'preservation by investigation' will be considered and, more specifically, the question of whether we should be pursuing developers to raise, conserve and display every hull structure that is excavated, recorded and recovered. This discussion will also raise the question of who should be driving the policy debate and framing and defining the arguments - industry and government, professional archaeologists, heritage managers, academics, divers or the 'public'.

This paper is not attempting to propose the direction maritime archaeological heritagemanagement policy should be taking, but rather to try to draw out some of the broader issues we need to examine. It is not an attempt to advocate one argument or another as the solution to any of these debates, but instead to demonstrate that these are complex issues that require proper consideration. Thus, from initial discussion of these management problems, further, more reflexive, questions will be explored in more detail. Some of the implicit assumptions which underlie heritage management but remain largely unscrutinized will be considered. Specifically, how we conceive of 'heritage' will be examined, along with what the discourse of our management debates, and the terms and language we use, highlights about that conception and the heritage narrative we subscribe to-one that conceives of heritage as a metaphysical reality, a tangible thing to be protected. This is linked to the notion of 'stewardship of the archaeological record'; consequently the implications of the increasing 'professionalisation' of maritime archaeology will be discussed, addressing questions of authority and legitimacy, of ownership and appropriation. Lastly, the ensuing question of who gets to define and produce the past will be explored. This will lead to consideration of the notion of the production of multiple pasts, or multiple dialogues with the past, as a less prescriptive and exclusive approach is proposed, and the possibility of space within maritime archaeological heritage management for 'alternative maritime archaeologies' is explored.

\section{Preservation in situ}

The now ubiquitous creed of 'preservation in situ' is intriguingly problematic under water, on the coast and in the inter-tidal zone. Under water the 
notion increasingly means reburial of archaeological material or attempts at site stabilisation. In many cases, a site must be exposed through erosion or changes in sediment regimes for it first to be recognised. All sites, exposed or not, are subject to entropy. However, exposure necessarily accelerates change in the biological, chemical and physical processes acting on the archaeological material. From the moment a site is uncovered it is degrading, often rapidly, and it requires active, sustained, physical intervention in order to be preserved in situ. Yet actual preservation remains unlikely, and intervention can only hope to change the rate of decay.

HMS Colossus, in the Isles of Scilly, provides an illustrative example. The stern of Colossus was identified in 2000, and the site is now designated under the Protection of Wrecks Act (1973). It is a remarkable site: a beautifully-fresh hull-structure surrounded by white sand, with generally good visibility (Fig. 1). There are several cannon, muskets and other artefacts visible on the sea-bed alongside the hull-structure. In addition, the vessel has an evocative history and an association with Admiral Lord Nelson. Over the last three years there has been a site-stabilisation trial under way, assessing three systems for attempting to encourage accumulation of sediment across the site and looking at, among other things, the scale and speed of deterioration of the hullstructure (Camidge, 2003). The results have now been collated (Camidge, 2005), and have raised the question: should we be covering the whole or part of the site in the geotextile Terram in order to encourage re-sedimentation?

During the trials, site-tours were run for local divers, but they were, otherwise, prohibited from diving on the site. Such exclusion has led to a growing feeling locally that there ought to be more open access, with some kind of visitor scheme in place to allow divers onto the site - that there should be an element of local 'ownership' or stewardship in the site's management. If vulnerable parts of HMS Colossus's hull are covered in geotextile, there will be a visually limited dive experience, as well as restrictions on the nature of research it is possible to undertake on the site. Yet it should slow decay enough to allow a programme of proper investigation and management to be established. Either way, a decision must be made. Currently there is simply decay by default (pers. comm. Camidge), and if the decision is left long enough, the quandary will disappear on its own.

There are evidently competing interests involved, and which direction the management of the site takes over the next few years will be telling. At the same time, this tension between access to the site and the consequences of physical intervention aimed at its stabilisation, and the management conundrum this creates, raise some weighty questions applicable to any number of maritime sites. The outcomes of such stabilisation measures as reburial are, for example, not certain. This is an area of research without any long-term guarantees; most research

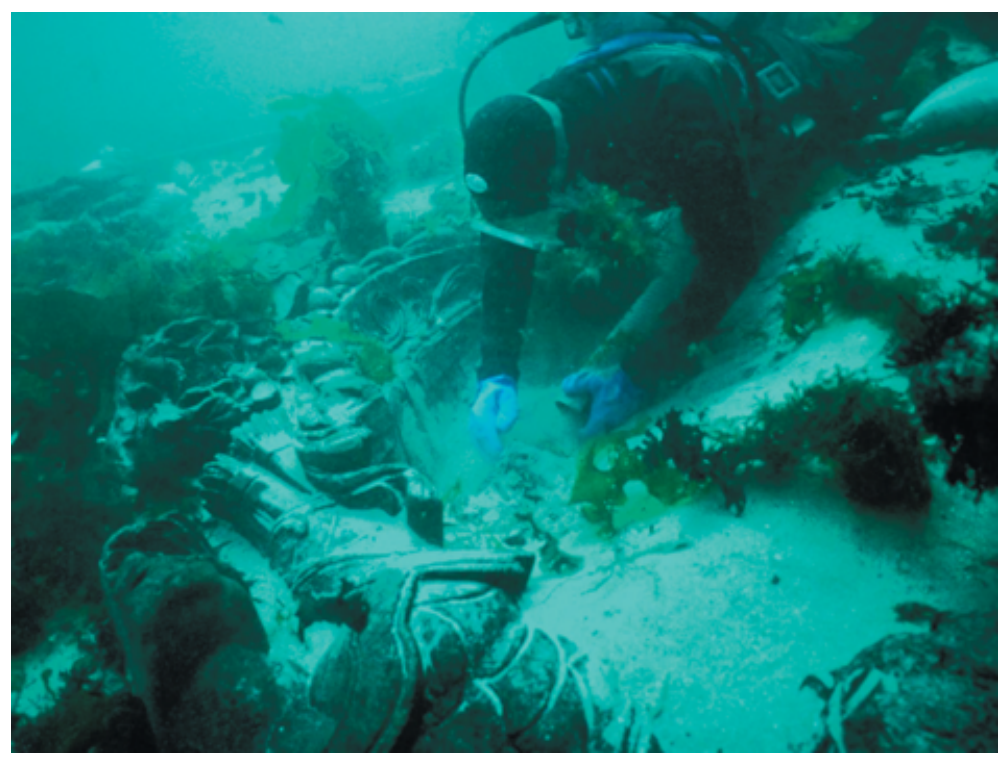

Figure 1. Decorative stern carving on the HMS Colossus site. (Kevin Camidge) 
projects are only beginning to scratch the surface of the complexity of the processes involved (for example, Palma, 2005). We do not know for certain that active and sustained intervention is always required or that it will be effective. So we ought to be asking questions such as, how long is intervention going to preserve the material remains for? Is this a question of decades? Or, are we simply battling against the inevitablefighting the marine environment rather than working with it. This last question obliges us to address a number of other issues, not least whether a stabilisation strategy is physically and logistically sustainable or affordable. Which ought, in turn, to lead us to ask how we justify the cost on this site rather than the other 44 English protected sites or the countless thousands that are not designated. How do we determine which site is 'valuable' or whether one site is more 'valuable' than another and therefore deserves intervention to attempt to preserve it in situ?

Finally, this case in particular requires us to address the complex question of ownership; for whom are we protecting these material remains? Certainly there is a path between complete reburial of a site like HMS Colossus and open access - one that allows compromise through local involvement, and schemes such as diver trails, alongside preservation of parts of the site. Although the question remains of how exactly the management and resource pressure involved in properly implementing such a scheme on even this single site would be sustained. We might also profitably question the assumption that public access to underwater sites is undeniably a good thing, and who 'the public' is. On land, many principal sites have restrictions on public access. Considering that divers are only a small, and relatively-wealthy, section of the public, should diver access be a priority over other forms of public interpretation above the water?

\section{Preservation by investigation}

The strategy of 'preservation by investigation', formerly 'preservation by record', is proving to be problematic in its application. Cases of shipwreck sites directly affected by development, which cannot therefore be 'preserved in situ', are arising more regularly. Moreover, the more maritime archaeology engages with development-consent processes and raises awareness within government and industry of maritime archaeological issues, the more cases curators and heritage managers will be required to make decisions on. Yet we have not established any consensus on what 'preservation by investigation' means in a maritime context.

Over the last few years, several cases have arisen in English ports alone as a result of activities related to the maintenance and development of shipping channels. One of these was the Princes Channel wreck in the Thames, which raised considerable debate among the maritime archaeological community and some heated public correspondence during 2004-05. The wreck was found by the Port of London Authority as the result of a grab-dredge of obstructions as it fulfilled its obligation to maintain shipping channels. After investigation and excavation of the disturbed site by an archaeological contractor, what remained of the wreck was recovered (Keys, 2004; Port of London Authority, 2004) (Fig. 2). Among the discourse surrounding this case, the most vehement discussion frequently returns to the ship's remaining pieces of hull-structure and associated timbers, and what is often characterised as the need for conservation and permanent display of the remains (comparable to the Mary Rose project), rather than comprehensive analysis and interpretation of the whole assemblage.

A similar concern is evident in the discussion surrounding the Newport Ship in Wales, which was identified in 2002 during construction of a new Arts Centre next to the River Usk. It is an illuminating example, not least because of the story of the 'Save our Ship' campaign, the Friends of the Newport Ship group, and 'the importance of this emotional ground-swell to the successful recovery of the ship' (Roberts, 2004: 158). The dynamics at play here, capable of overcoming the inertia of beginning such a large heritage enterprise, include notions of national and cultural identity and the role heritage plays in producing and maintaining those constructs. However, it is the perceived necessity for preservation of the actual, physical ship timbers, visible from the beginning of the campaign, that is most telling.

'Following the announcement of a discovery of the timber remains of a mediaeval ship, Newport City Council announced that 'only $5 \%$ of the timbers will be preserved', and the vessel was scheduled for destruction despite unprecedented local and international interest' (Friends of Newport Ship website).

It would be derisory to suggest the ship is not both rare and worthy of thorough study 


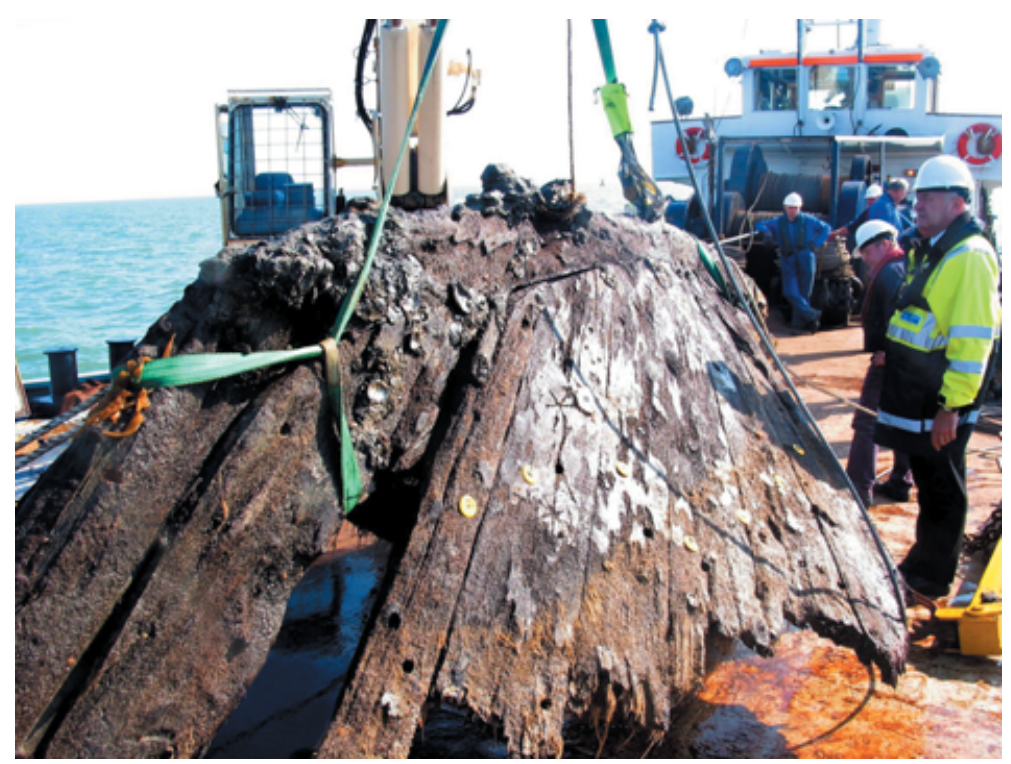

Figure 2. A section of the Elizabethan (16th-century) wreck being recovered from Princes Channel, Thames Estuary. (Wessex Archaeology)

(Roberts, 2004). However, with a programme of recording as comprehensive as that already under way and funded by the Heritage Lottery Fund, the value of conservation and display of the actual vessel remains could be reasonably debated. Certainly, in the context of the large funds it will require, it is plausible to query whether this element of the project and this single ship can justify those funds over other projects and other sites. What is interesting, however, is not whether this alternative argument is persuasive, nor even the unusual passion and emotion these ship remains have been increasingly invested with, but the fact that there has been no debate about the validity or necessity of conservation and display. Debate has focused on how, where and how much, but not why. However, most pertinently, there seems to be an assumed correlation between those 'important', 'more complete' or 'early' vessels that have been recovered (all of these descriptors being both subjective and emotive), and conservation and display of their hulls. Influenced by the long shadow of the Mary Rose and Sweden's Vasa project (During, 1994; Marsden, 2003), which have embedded this imperative to conserve and display whole hulls in our understandings of shipwreck heritage, there is a lack of debate over excavation and recording standards, material and documentary archives, interpretation and publication.

Both these cases raise the very basic question of what should become of hull structures when investigation, excavation, recording, analysis and publication are complete. Even if we were able to compel developers to pay for the conservation of every ship hull raised, would this be appropriate? Such a strategy would require us to ask ourselves where we envisage putting them all, and how many could be feasibly and productively displayed. This somewhat extreme proposition is clearly an unrealistic one, and yet the discourse about both the Princes Channel wreck and Newport Ship emphasizes the need to preserve the physical remains of the hulls of 'important' or 'significant' vessels. Should we therefore be attempting to conserve and display only the most important hull remains? Clearly, this is a solution that would then require us to determine which are 'the most important' and to ask who ultimately should make such decisions on the question of value and importance.

It is sometimes suggested that the alternative is some form of reburial of excavated remains elsewhere. Questions of feasibility and sustainability are equally pertinent to this suggestion, not least whether there are enough lakes and areas of undeveloped sea-bed available and who would be responsible for managing them. However, this solution also highlights the central question in this debate; assuming hull structures would be preserved by reburial in a different environment (and that is a large assumption), for what purpose would we be trying to preserve them? It does not seem unreasonable to suggest that, given the approaches taken to wooden structures on terrestrial sites, it would be valid to 
record them, conserve and archive only the most unusual features of construction, and then dispose of them. Most fundamentally, beneath the 'oughts' and 'shoulds' in the discussion of individual cases, remains the question: are those ship hulls in themselves the heritage we are trying to preserve for future generations? In the end, and most fundamentally, we need to determine whether we are interested solely in those physical remains or whether it is the information they yield, and the potential for new interpretation and further insights into past communities and past lives, that is of importance.

As this discussion has so far sought to illustrate, underneath the often personalised and emotive discussion surrounding specific cases and management decisions, lies a series of fundamental unarticulated questions which remain unresolved, and undermine any potential consensus or more judicious debate. Rather than moving blindly forward we need to examine these underlying questions thoroughly. Clearly we need to consider the position from which we begin and the assumptions we are making when we talk of 'heritage' or 'the public'. If we are to reach a working consensus within the maritime archaeological community on policy and strategy, we must begin to employ the self-critical analysis and reflexivity that has so far been lacking in our heritage-management debates.

\section{Concept of 'heritage': language-games}

'Occasionally we might want to remind ourselves of the truism that every past is the construct of a particular present-day context' (Holtorf, 2005: 549). It is worth acknowledging first, given the cases discussed so far, that maritime archaeological heritage does not equate solely with shipwrecks. However, it is not the types of archaeological site which comprise our maritime heritage but our conception of heritage that is of concern here. Are we discussing those ship hulls, or the information they yield; our interpretations of that information, or the potential link they provide to orientating our present to our past? The term is so easily used, but what is it we actually mean by 'heritage'?

The discourse surrounding archaeological heritage characterises it as something to be preserved, to be mediated, explained and interpreted by archaeologists. But above all this discourse portrays heritage as something to be protected. A sense of 'rights' is involved, along with ownership — my heritage, our heritage - and these are linked to community identity and associated, more ephemeral, notions of posterity, future generations and preservation as an expression of communal resilience (Skeates, 2002; Edson, 2004; Carman, 2005).

This characterisation is repeatedly conjured up through the terminology we use, with the metaphors this specific language creates serving to support and reproduce our particular conception of heritage. As a consequence, it also provides a distinctly illustrative way of examining that conception and the structures and agendas it supports (Wittgenstein, 1958: Aphorism 115; see also Harris, 1988). Dowson, for example, has touched on the language used in archaeology when discussing the term 'fragile heritage' in Rock Art studies. In this context, he addresses the manner in which need for protection evoked by the metaphor is used to justify establishment and masculist approaches to the archaeology (pers. comm.; see also Dowson, 2001). It is also a metaphor we use regularly in our discussions of maritime archaeology. 'Fragile heritage' evokes a thing that is breakable, weak and finite - that is being washed away. It requires protection, an almost paternalistic approach to the material remains of the past, where we, the archaeologists, need to look after this passive, delicate thing for its own good, for the public, for posterity. 'Historic asset', another term used regularly in heritage-management discourses (including the recent UK heritage protection review undertaken by the Department of Culture, Media and Sport), is equally expressive. It suggests something valuable, of importance, something precious and worthy of protection. Yet it also draws on the language of economics, implying something that has been valued and commodified, something weighed up and quantified, but above all, a thing. Of course, if we are to have a 'heritage industry', then we ought not be surprised at the commodification of heritage as assets.

It is also worth considering the phrase 'marine historic environment'. It slots beautifully into the language of Environmental Impact Assessments, of large-scale developments and the associated government regulatory systems. During the planning phase, the impacts of a development on the environment must first be assessed and then mitigated where possible. This includes impacts on the historic environment. This is a version of the past constructed totally through the prism of industry, and yet again, it is one represented as static, inert, passive - a physical, finite thing. 
Moreover, it is a thing separate from the present environment, no longer part of modernity, nor changing and altering constantly through cultural, biological and physical interaction with the modern world. The term 'archaeological resource' is in many ways equally symbolic (and provocative), as Carman has already discussed in some detail (2005; see also Wylie, 2005). Suffice it to say that in observing that, "we have allowed the domination of a "resource" model that inevitably leads to the adoption of an "economic" understanding of heritage management issues', Carman (2005: 121) highlights the implications of the increasing integration of our heritage structures with industry (and the associated economic and socio-political systems). At the same time, he also provides the explanation for the economic language interwoven with heritage language.

In fact, we construct heritage as a thing whether we cast it in the light of current socio-economic mechanisms and their accompanying terminology or not. Our discourse presents an abstracted object, an entity to be managed-something that is tangibly out there, a bounded and objective mass that is both fragile and in need of protection-rather than a modern, cultural construction, that is just one version, one interpretation, of the past.

It is something of a recognised maxim that archaeologists are not simply 'reading' past truths from the material remains left behind and objectively reconstructing the way things were, but that the past is the product of the present. Johnson stresses that archaeology does not exist within a vacuum, since 'we are unavoidably influenced by our social and political circumstances' (1999: 175). Gadamer's idea of establishing a relationship between the past and the present to which we bring our assumptions and conceptual baggage, or in his words 'the tyranny of hidden prejudices' (1975, cited in Thomas, 2004: 1), has been pursued in archaeology by Shanks and Tilley (1987) among others (Thomas, 1996). Holtorf points out that 'academic knowledge is constructed in the present and not directly related to past realities, but follows fashions and changes according to larger political, ideological and academic trends' (2005: 540). Thus as archaeology cannot be abstracted from our sociocultural context, neither can heritage. Heritage is not a given. It has no empirical reality. Instead the concept itself, as well as the conception, is socially constructed (and arguably, it is, to be specific, a construction of the modern West). Our construction of 'heritage' is the product of the political, cultural, economic and governmental present, and a rather socio-politically charged version of the past. This has been explored and demonstrated in a number of ways, not least through the study of the interactions between nationalism and heritage (for example, Meskell, 1998; Evans, 1999; Hamilakis, 2002), and nationalism and archaeology (for example, Trigger, 1989; Fawcett and Kohl, 1995; Diaz-Andreu and Champion, 1996).

The highly emotive nature of heritage, despite our construction of an inert and objective entity, illustrates this point well. In much of the literature discussing the concept of heritage, authors are careful to qualify their discussions, emphasising that they are not arguing for or condoning unregulated access to, or dispersal of, cultural artefacts, but examining the notion of heritage itself. This, for example, is from the abstract of Edson's paper, 'Heritage: Pride or Passion, Product or Service?':

... what is the heritage that is being protected and promoted? This paper is a commentary on the theoretical basis of heritage. The questions posed and the ideas offered are not intended to condone the unregulated movement of cultural and natural materials (heritage) in any form. The plunder of archaeological sites, the theft of cultural and natural objects and specimens, and the destruction of structures and locations for profit or during times of conflict are heinous acts. These activities incite the spoilage of history, deplete traditional values, and degrade the basic notion of human decency. Nevertheless, the question remains: 'what is heritage?' (2004: 333).

That Edson feels compelled to take up more than half his abstract with this apologetic, despite the fact that he is simply examining a theoretical concept within an academic forum, is revealing. There is an implicit expectation that people will react negatively without examining his discussion properly. This careful reticence on Edson's part is probably best explained by his observation that 'the idea of heritage has greater symbolic meaning than the object, time, or place, that is, the historical reference' (2004: 338). This in part explains the dissonant discussions surrounding specific maritime archaeological cases. Though it does not justify it, nor belie the fact that beneath these discussions are fundamental and unanswered questions which undermine potential consensus.

Andrews' exploration of the identity politics of underwater cultural heritage in Bermuda provides 
a clear illustration of the symbolic power of notions of heritage as well as its mutability. She examines the contested space where 'heritage' is shaped and claimed in opposing ways by both 'salvage divers' and archaeologists or museologists and provides a particularly valuable illustration of the complexity of this interplay (Andrews, forthcoming). Edson's description of 'heritage as a social phenomenon' is therefore particularly pertinent (2004: 343). Edson suggests that 'not only is the conception of heritage often not absolute and the resource not permanent but also the conception and association of the resource is subject to historical mutability' (2004: 345).

Though the language we use and the discourse around our heritage may present a passive, valuable thing to be acted upon or for, heritage has no empirical reality. It is, in fact, a social phenomenon. It is a cultural construction created within a particular social context, one version of the past inscribed by our socio-political present. It is neither inert nor objective, but emotive, mutable and often personalised-produced by and in turn reproducing the social structures surrounding it, supporting and reinforcing specific cultural identities. This, surely, has direct bearing on how we debate maritime archaeological heritage. The 'establishment' version of heritage is only one version, and one which is formed within a particular socio-economic structure, that of industry and its resource model, and the commodification and commercialisation of archaeology and heritage. Yet not only is heritage a product of the modern West and the capitalist structures inherent within that, but the multiple discourses of power-relations which are implicit within the historical specificity of the term necessarily produces a series of tensions through which many understandings of heritage are generated. We need to acknowledge that heritage has varied meanings for different people, and that as a social phenomenon, the cultural action involved in defining and producing it is of fundamental importance. In which case, we ought to be questioning how the notion of heritage has become so narrowly prescribed, and querying who gets to determine it.

\section{Professionalisation and appropriation}

'Constructions of the past serve different social interests, and thus have consequences for wider society' (Duke and Saitta, 1998: 1). The discursive construction of heritage as an abstract, fragile entity is linked inextricably with the positioning of archaeologists as self-styled protectors of the past. We are the guardians or gatekeepers, who manage and mediate the physical remains of the past, preserving and interpreting it. This construction of heritage is used by archaeologists as part of the process of defining and asserting a 'professional' identity. The recurrent claims of archaeologists to stewardship of the 'archaeological record' (for example, Smith, 2004: 81104) are central to that professional identity. The 'archaeological record' is imagined as another physical and finite thing. Hamilakis suggests that it is 'a metaphysical entity that has been produced by archaeologists themselves out of the material fragments of the past' $(1999 ; 2005$ : 99); a notion interwoven with our construction of heritage.

There has been considerable sociological analysis of the process of 'professionalisation', and Taylor has discussed the professionalisation of archaeology in particular, exploring the narrative, as told by archaeologists, of the shift from 'amateur', 'dilettante' or 'dabbler' to professional, from antiquarian to archaeologist (1995: 500). There are undoubtedly considerable benefits to the professionalisation of maritime archaeology. Not least is the notion of 'professional ethics and standards', with increased accountability, improved transparency, and clarity of research objectives. Professional standards also act to confer legitimacy on archaeologists' activities, and provide a place from which to argue the archaeological corner with industry when necessary.

However, it ought to be of interest, and perhaps concern, that establishment of the legitimacy and authority of professionals is the essential substance of professionalisation. Within his discussion of the professionalisation of archaeology, Hamilakis argues that the legitimacy of archaeologists' actions "rests on the "professional ethics" that recognise, as a primary ethical responsibility of archaeologists, the preservation and stewardship of the 'record' (2005: 99; see also Hamilakis, 1999; Wylie, 2005: 60-65). Certainly, professional archaeologists both subscribe to and employ this reified construction of the archaeological record in order to validate our positions. As a consequence, we prioritise and legitimate certain types of archaeology (for example, Schofield and Anderton, 2000), certain kinds and circumstances of work, certain groups and certain sites. In maritime archaeology there is, for example a clear preference for certain types of shipwreck site (such as named vessels with 
'back stories' and links to British imperialism and historical naval power), over others (such as vernacular, local or working vessels) (for further discussion of epistemological privilege in maritime archaeology see Ransley, 2005). These prioritising decisions are all taken on behalf of a passive resource for a passive, hegemonic public. For despite the fact that 'the past belongs to all' (Merriman, 1991: 1), the 'public' has very little to do with actual people, let alone individuals, in the context of archaeological heritage management. Carman suggests that, 'the literature of heritage management abounds with limited concern with "the public" as groups of people: as visitors, tourists, sources of revenue and capital funding, as audiences and as customers' (2005: 46). All of the categories he identifies are passive groups, who professional archaeologists act on behalf of, protecting, preserving, explaining and mediating the archaeological record for their good. Clearly, then, there are active power-dynamics at work within this idea of professional stewardship.

As professionals protecting the archaeological record, archaeologists appropriate it. It is this implication of professionalisation above all others that demands examination and that regularly impacts on the wider community. As a group, professional archaeologists are in danger of making heritage exclusive, accessible only through us and on our terms (Zimmerman, 1995: 65). Zimmerman's critique of the stewardship principle has been expounded by Wylie: 'by unilaterally declaring themselves stewards of the archaeological record, archaeologists were essentially foxes setting themselves up to guard the chicken coop' (Wylie, 2005: 55; see also Wylie, 1996: 181) (though there is perhaps less danger of this within maritime archaeology where the precedence given to the conservation ethic over-rides even scientifically-conceived, research-driven excavation). To return to Hamilakis, professional archaeologists appear to be 'always holding the highest of professional standards [for their work], but never questioning ... the broader dynamics of power in which that work is inscribed' (2005: 100; emphasis added).

In light of this comment, it is also worth considering the implications of the term 'archaeological resource' discussed earlier, and the consequences of the commodification of the material remains of the past and of 'heritage', and the embedding of archaeologists into ascendant, socio-economic and political systems as a consequence of professionalisation - a full discussion of which is beyond the scope of this paper, though nonetheless important. It is worth noting in passing, however, that the shift from university-based to contract-unit-based archaeology has had a profound effect on how we think about and practise archaeology. Wylie refers to 'cultural resource management', with its ethical tensions and 'complicated network of competing responsibilities to a range of stakeholders', as the final driver towards redefinition of what was a research-led discipline (2005: 59). Contract archaeology might not, therefore, be the best medium for examining strategic heritage-management issues or encouraging debate over the increased commodification of our heritage, nor should marine industries be allowed to drive policy-making or the development of maritime archaeological guidance and standards.

Hamilakis's 'broader dynamics of power' and this problematic notion of professional archaeologists as guardians of the archaeological record can manifest itself from time to time in somewhat distasteful ways. The emotive nature of heritage has already been touched upon, and it is worth noting that impassioned responses to any discussion that is perceived as negative or threatening are common among professional archaeologists. No doubt this is in part due to admirable enthusiasm for, and commitment to, their work, alongside a natural emotional investment in notions such as the archaeological record and professional ethics. However, this has revealed itself on occasion in inexplicably aggressive attacks on alternative archaeological discourses. McManamon, for example, has argued that professional archaeologists should be actively challenging 'pseudo-archaeologists' and their 'misguided interpretations' (2000: 6) and suggested that 'the distortion of archaeological interpretation by looters, misdirected hobbyists, some developers and different kinds of charlatans is of great concern to all in the field' (2000: 5). His polemic did not go unquestioned. Holtorf asked,

On what authority is anybody entitled to divide up their fellow citizens into categories such as 'charlatans' and 'misdirected hobbyists'? Surely such judgements, as they are socially negotiable and subject to change over time, tell us more about the person making them than about the people addressed or should I say insulted (2005: 545).

Holtorf's colourful riposte to McManamon's 'crusade' is equally disputatious, 
'... intellectual crusades are not required for making a positive contribution to society. Archaeologists do not serve as a special state police force dedicated to eradicating interpretations that are false or inappropriate by a self-selected jury.' (2005: 549; see also 2000).

But it highlights both the appropriation of archaeology by self-styled professionals and the potential intolerance, and pomposity, that this can breed. More importantly, it demonstrates a failure to acknowledge that there may be more than one dialogue with the past, and more than one version of it.

Appropriation of heritage, archaeology and access to the past is also evident in a more insidious, and possibly equally distasteful, way in the informal 'ownership' that is often acted out over sites by individual archaeologists. It is visible in that unwillingness to make it possible for others to investigate, or in some cases visit, a particular site, or to draw on the site archive to pursue and publish different interpretations. This is particularly evident in the brief history of maritime archaeology in the UK, and an ungenerous observer might suggest that in some cases this reflects a rather ugly insecurity (since only by recording the evidence comprehensively are different interpretations facilitated), acted out through a form of archaeological protectionism. While there evidently should be a respect for ongoing work, there should not be an embargo on any other study of a site; there should not be an appropriation of the site.

This discussion might appear somewhat abstracted from the more practical questions with which the paper began. However, on a basic level, whether or not we decide to try to preserve a site through reburial, or facilitate public and research access, depends upon on the value we give to the preservation of those material remains in comparison with the potential dialogue and interaction with the past that access to that material offers - the potential for the production of other archaeologies by other groups. It depends on our conception of heritage and the role that professional archaeologists chose to take; it depends on whose archaeology it is. Both the issues surrounding 'preservation in situ' and 'preservation by investigation' in maritime contexts, return repeatedly to the problem of who gets to make these decisions, and on whose behalf, and on what authority, they are made (see Wylie, 2005: $61-5$ for further discussion). Driven by the notion of preservation of the record and of 'professionalism', professional maritime archaeologists are in danger of marginalising other groups and appropriating the right to define our communal 'heritage'.

The notions of legitimacy and the authority professionalism presents both rely on this characterisation of heritage and the archaeological record as a metaphysical entity to be protected. Once it is diluted by recognition of the fact that heritage is a social phenomenon, part of the process of the production of communal identity, the more arrogant manifestations of professionalisation are shown to be inherently flawed. Quite separately from any question of the recognised skills and knowledge-base of professional archaeologists, we ought to be asking if this elitist, appropriating approach is the right one.

\section{Professionals and amateurs: labels}

There can be no self-defined amateurs until they can be condescended to by self-defined professionals. The rise of professionalism may, in certain specific cases, require the decline of the enthusiastic amateur (Taylor, 1995: 502).

Until well into the 1990s, maritime archaeology in the UK was largely undertaken by 'amateurs'. Many of today's 'establishment' figures began as volunteers on shipwreck excavation such as the Mary Rose or Yarmouth Roads projects. Yet there is a tendency amongst the academic and professional community to patronise non-professional maritime archaeologists (this is, of course, only my opinion though it is based upon recent experience). This kind of paternalism, symptomatic of appropriation of the right to define and interpret the past, is the ugliest part of our reification of the archaeological record. Paternalism is also, however, in some ways a predictable consequence of the rise of the professional, and identifiable in any number of other fields.

Within the body of literature discussing the relationship between professional and amateur status, the characteristics which determine a profession are in general concerned with how they differentiate themselves from non-professionals (Stebbins, 1992; Robbins, 1993; Taylor, 1995). In order to define professional identity, a group needs to define what it is not. However, even if this phenomenon is explicable, and visible in the historiography of archaeology, it still deserves more concerted examination. The results of what is in itself a fairly innocuous process of the 


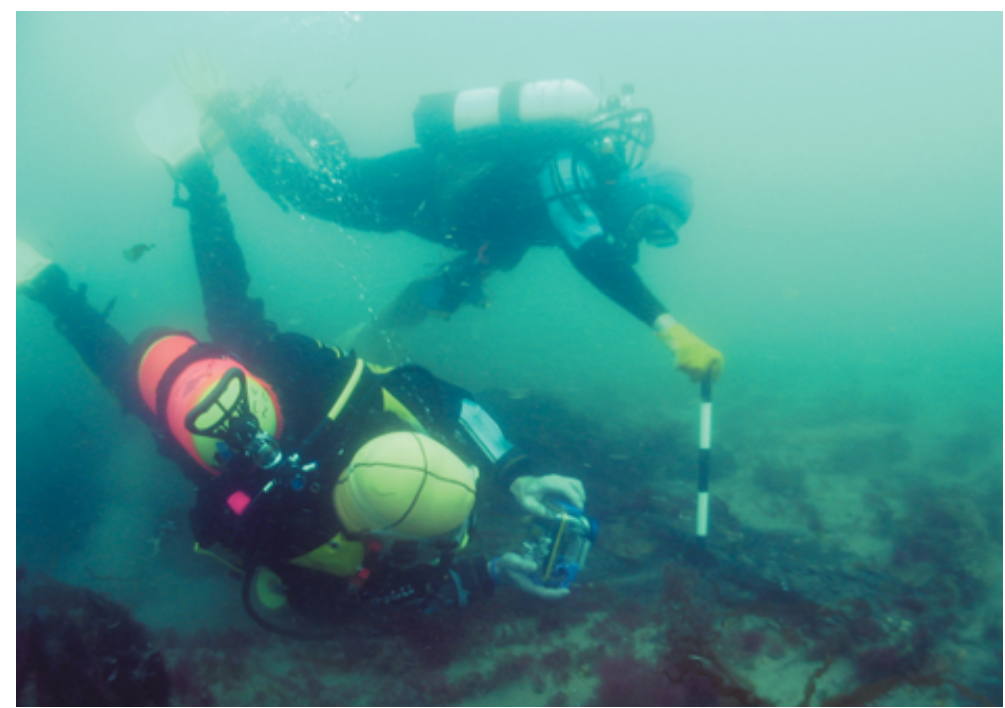

Figure 3. Avocational and professional archaeologists working together: on the Solent Marine Archaeology Project (SolMAP). (Hampshire and Wight Trust for Maritime Archaeology)

creation of professional identity - differentiation of professional from non-professional, and definition of professional standards and ethicsare not always as innocuous. An explanation of its origins, such as that presented by Taylor (1995), does not undermine the need to examine and determine how this is acted out.

If we return to Dowson's technique of unpacking the metaphors which archaeological language generates, we have a wealth of examples of terms used for non-professional groups and individuals involved in archaeology and archaeological sites. There are a limited number of vaguely constructive terms 'amateur archaeologist', or the currentlyascendant and apparently-more-acceptable term 'avocational archaeologist'. However, they both define the individual by what they are not-that is, not professional with all its associated legitimacy and authority. Other terms frequently, and often unfairly, used include 'hobbyists', 'collectors', 'wreckers', 'salvage divers', and most damningly 'treasure-hunters' (there are of course a few more vernacular descriptions not suitable for publication). The most contentious of these labels is also the most evocative - 'treasure-hunter'. It presents a wonderfully revealing metaphor: hunting, actively seeking out, killing and destroying things of value, suggesting people only interested in economic value and monetary gain. In contrast, as I have discussed, legitimate archaeologists are presented as caring for and protecting the archaeological record. It is one of the most telling terms, because it sets archaeo- logists up in direct opposition, in conflict, with moral and ethical ascendance on their side. What is important is the liberality with which these implicitly derogatory terms are used and the fact that we have not established a comfortable terminology, or are not able to simply refer to non-professionals as 'archaeologists'. The whole issue should surely be re-framed in the context of the quality of the archaeology rather than the status of the practitioner; yet we return to these labels.

It would be unfair, however, not to acknowledge that there are professional archaeologists who have worked and do work successfully in partnership with non-professional archaeologists (in England notable current examples include work undertake by the Cornwall and Isles of Scilly Maritime Archaeology Society and the Hampshire and Wight Trust for Maritime Archaeology) (Figs 3 and 4). It would be equally unfair to infer that this is all a game of 'them and us', acted out by professionals on a victimised or passive group of non-professionals. There are discursive constructions of non-professional maritime archaeologists as 'plain-speaking' (and another favourite 'a practical man'), set up in opposition to heritage managers and the archaeological establishment. The language of heritage management is often a barrier between 'professionals' and 'amateurs'. The acronyms and management-language which trip off the tongue so easily when you are in the middle of management organisations can often alienate 


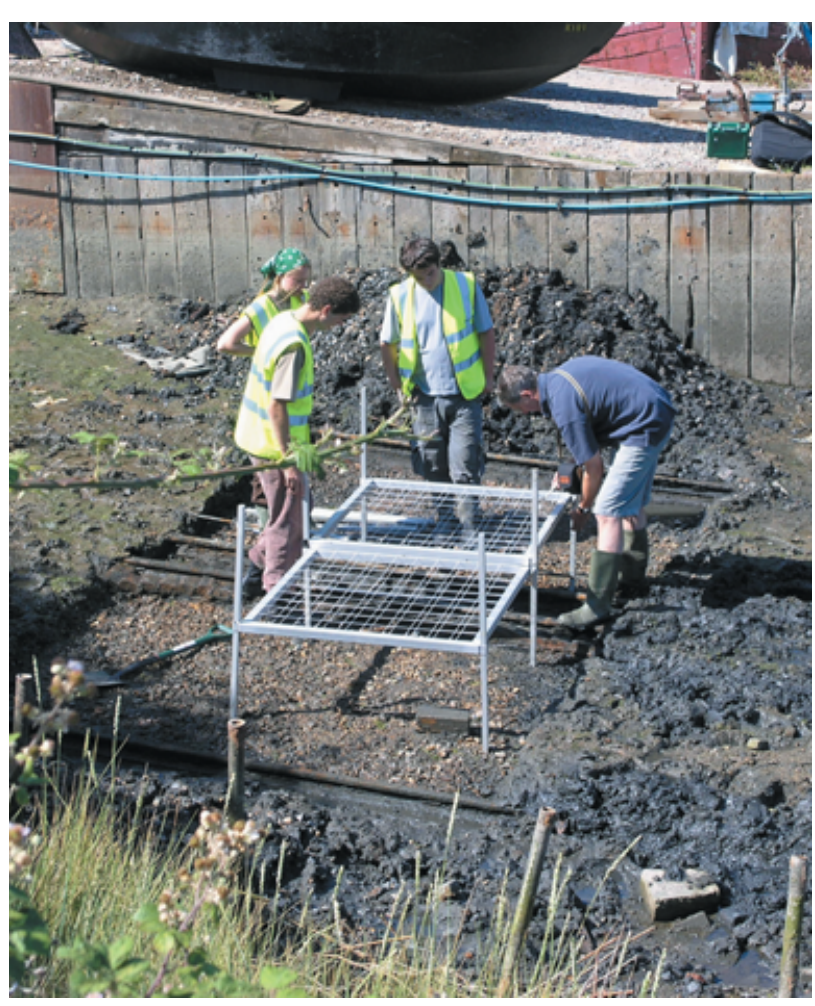

Figure 4. Avocational and professional archaeologists working together: on the Forton Lake project, Gosport. (Hampshire and Wight Trust for Maritime Archaeology)

and frustrate other groups. In fact, it can be deliberately used as a barrier, a wall of terminology to smother an irritating debate. At the same time, this language is often ridiculed, and there are individuals guilty of simply switching off when it is employed, even when the arguments are coherent, logical, practical, (and even in one notable case to their advantage), simply because they have positioned themselves as 'plain-speaking, practical men'.

However, the dangers of this polarisation of 'them' and 'us' remain. One is the tendency to lump commercial treasure-hunters and amateur archaeologists together as outside legitimate archaeology. Yet there are a number of amateur maritime archaeologists who are both knowledgeable researchers and skilled practitioners, with motivations as laudable as those of any professional, and probably more skilled and accomplished than an equal number of 'professional' maritime archaeologists. Moreover, it remains a fact, though we may wish to skirt around it, that there are 'professional' archaeologists who lend their names and support to, and even take part in, 'treasure-hunting' activities.
The ease with which the contrasting motivations of such disparate groups are blended within our heritage discourse, and our failure to differentiate and address them differently, is disquieting. There is a danger that 'amateur' becomes connected to the ethically and methodologically dubious practices of treasure-hunters. Yet there is a fundamentally important difference in the motivation of acquisition and personal profit behind treasure-hunting activities, at whatever scale, and the legitimate desire to investigate and engage with the past.

This is starkly visible among some of the groups which are licensed to work on UK shipwreck sites designated under the Protection of Wrecks Act (1973). Some groups have been monitoring and researching particular sites for decades, and together have produced and are part of a parallel knowledge base. In practice most sites only have work undertaken on them by Licensees, and in many cases the question becomes what is made of that work, how it is supported, progressed, archived and disseminated properly. This does not go unacknowledged within the maritime archaeological community, but is always accompanied by actual or implied caveats; that sense that this work is 'good for an amateur'. The underlying notion remains that non-professional archaeologists ought to be advised and managed. They ought to be controlled in the way they work and what they do, to be taught better by professional archaeologistsmaking them 'good' amateurs. Yet what constitutes a 'good' amateur is always something the professional body gets to define and confer. Thus we come back to the question of whose archaeology, whose heritage, it is?

One notable English example is that of a group of amateur archaeologists and divers who in the 1990s investigated the site of a 17th-century wreck, which yielded among the artefact assemblage a considerable quantity of gold coins and jewellery. This material went to the British Museum and the finders received a substantial award. As a result they have been characterised by some, both professionals and amateurs alike, as treasure-hunters, divers looking for shiny valuables. They are not unaware of this label, and are understandably somewhat defensive about it, since it questions their motivations, their work and their right to be part of legitimate archaeology.

Secondly, after this material was accessioned to the British Museum, there was subsequently a 
somewhat sparse and frustrated dialogue. This typifies the sense that this group became excluded from the archaeology, since the information and discussion, the thought and research, seemed to have been appropriated along with the coins and jewellery, (it is worth noting that the discovery has led to research outcomes that would not have been possible without the interest and involvement of the group). In some senses, they were made to feel they had merely supplied the artefacts to a larger system. However, this material had meaning for them, bound up with the process of engaging and connecting with the pastproducing the past.

\section{Multiple pasts, multiple dialogues}

'Archaeology, as cultural practice, is always a politics, always a morality' (Shanks and Tilley, 1987: 212). If we recognise that the past is a product of the present, in our approach to heritage, and that professional archaeologists do not have some metaphysical authority over access to material remains of the past, then surely there is the potential for multiple engagements with the past, multiple archaeologies, each as legitimate as the other? Work by Licensees may not represent the mainstream of academic or contractor archaeology, but it is simply an alternative archaeology, and we ought to advocate alternative archaeological epistemologies.

It is worth clarifying that in this context, the term 'alternative archaeology' is not used in the sense of neo-shamanism, and other interpretations termed variously 'fringe, cult, fantastic, pseudo' (Holtorf, 2005: 544), (see also Merriman, 1991; Wallis and Lymer, 2001; Wallis, 2003; SchadlaHall, 2004). It does not refer to, for example, the pseudo-scientific, alternative maritime archaeology of Hancock (2002). Instead it is used to mean archaeologies outside the mediation of our professionalised framework, but equally legitimate, the idea of multiple dialogues with the past. The idea of 'alternative archaeologies' in the discourse surrounding neo-shamanistic or alternative interpretations, even among those who advocate engagement with these discourses (for example, Schadla-Hall, 2004; Holtorf, 2005), is somewhat restricted. The practice of archaeology, the doing, is still left to archaeologists and the classes of information, the types of sites and the 'factual' knowledge is provided by them, so that the alternative element is the interpretation and consequent desires about the treatment and management of 'heritage sites'. Skeates' discussion addresses them explicitly as 'alternative interpretations', rather than 'alternative archaeologies' (Skeates, 2002). There is very little notion of these alternative archaeologies involving investigation of archaeological material and sites, intrusive or otherwise. Rather discussion focuses on the cultural meaning built around alternative interpretations of archaeological data. So physical access to the material remains of the past, fieldwork, is still mediated by professional archaeologiststhe 'proper' practice of archaeology and the underlying dynamic of appropriation is not altered.

However, the practice of archaeology-survey, recording, excavation-ought to be part of alternative archaeologies. As Tilley points out, 'excavation has a unique role to play as a theatre where people may be able to produce their own pasts, pasts which are meaningful to them, not as expressions of a mythical heritage' (1989: 260). Interpretation, that engagement with the past, begins from the moment an individual enters the field, visits a site, makes a decision about where to survey and how, or chooses where to place a trench and why. Holtorf suggests that the significance of archaeology does not lie in specific knowledge gained, but in the 'process of engaging with the material remains of the past in the present' (2005: 544), as a consequence it can not be appropriate for professional archaeologists to be the only ones allowed to access those material remains.

This is not to suggest that there ought to be some kind of archaeological free-for-all, or that we should be abandoning the idea of preserving the material remains of the past, but that we ought to be examining the idea properly. In Hamilakis' words I am arguing,

for the problematisation of the notion, for an examination of the power and political dynamics in each context (Who wants to destroy what and why? Who wants to preserve what and why?); and, more importantly, for an ethic that rejects the fetishism and the self-serving principle of the "stewardship of the record" (2005: 100).

This does not imply archaeological anarchy, but self-critical examination of motivations by nonprofessional and professional archaeologists alike.

Just as the archaeological establishment ought to approach the material remains of the past without that sense of appropriation and with a notion of communal ownership, others should be addressing it with the same attitude. Public heritage surely implies a communally-minded 
and responsible approach by all groups. A true sense of multiple engagements with the past and alternative archaeologies does not give licence to individual members of society to lay claim to their bit of the past, rip it out and take it home. The ethical impetus for reflexive examination of their position and their potential appropriation of heritage, applies just as much to those outside the 'professional' archaeological establishment. Appropriation by other groups is not the solution and not what should be understood as alternative maritime archaeologies. The informal ownership of shipwreck-sites by divers can, for example, be seen as another form of appropriation of the past, equally distasteful as that articulated by McManamon (2000).

At the same time, equal engagement also implies equal scrutiny, in effect an equality of rigorous critique. Holtorf asserts 'all accounts are not equally valid or legitimate' (2005: 549), but argues that they all ought to be treated with the same respect. He argues for 'critical understanding and dialogue, not dismissive polemics,' and points out persuasively that, 'the true danger does not lie in the epistemological relativism inherent in my proposition but in the indefensible absolutism in the alternative' (2005: 550).

This is, I realise, a difficult area to navigate. The practical application of these ideas is in some ways a little disquieting, especially when much of our discipline is still grappling with 'recognition of the plurality of valid archaeological interpretations and the inability of archaeologists to discover a single true explanation of the past' (Schadla-Hall, 2004: 256). Though it has been argued that we need to maintain some degree of positivist empiricism in our examination of the past (Wylie, 2005: 63), to promote rigorous and 'rational' reasoning (Schadla-Hall, 2004), it must still be acknowledged that all constructions of the past are subjective, and that it is therefore fluid and diverse. Beneath this conceptual challenge, however, there remains a reassuringly tangible difference between the alternative archaeologies of, for example, Licensee groups, and the pseudo-scientific interpretations of Hancock and his ilk. In practice, any intellectual struggle we may experience results from our perceptions of professional and amateur archaeology, of 'legitimate' archaeology, and is therefore not such a complex theoretical problem, but a question of personal dogma.

In the end, this becomes a question of our ethical and moral position and whether we are capable of acknowledging the unsettling but significant value of multiple engagements with the past. We cannot ignore the present in the production of the past, 'different visions and experiences of the present constitute a range of contexts in which the past and it remains are given meaning' (Holtorf, 2005: 549). Hamilakis has proposed that archaeologists 'should be regarded not as 'stewards of the material record' but as 'cultural producers' (McLucas, 2001: 75). $\mathrm{He}$ argues that 'as story-tellers who participate in the field of cultural production by providing representations and narratives about past people, archaeologists should accept the responsibility that follows that realization'. For Hamilakis that responsibility includes 'the political economy of archaeological practice, the social consequences of archaeological work and its products, the politics of consumption of archaeological knowledges' (2001: 91; see also Hamilakis, 1999). This material is used dynamically within fields of modern cultural production; the past is an arena through which we negotiate modern cultural identities. This is an inherently subjective activity, and therefore not something archaeologists alone have a right to mediate. Thus in her discussion of museums' representation of 'archaeologically alternative' identities in Bermudan heritage discourses, Andrews suggests that 'while consensus and negotiation is desirable, the point of inclusion is not capitulation, but the opportunity for expressing different understandings' (forthcoming: 7). If we pursue only one type of truth - ours - and only one way of doing this - ours - we exhibit a remarkable arrogance and miss out on all the other potential understandings of the past. Edson asks 'where does the value of heritage resources lie - in the physical form or the value form?' (2004: 345). The value is surely in the interaction with it, in the processes of inclusivity, in the production of cultural identities.

Moreover, if heritage and archaeology are culturally constructed, than surely by attempting to control and determine which version of the past is prioritised as correct, we are undermining its value. Engagement with, and interpretation of, the past is an act with relevance in the present, interaction with the material remains of the past, with stories, varied interpretations and narratives are the means through which people orientate themselves to the past' (Edson, 2004: 338). Do we have the right to limit, define or control that process? Is that even possible? We have returned once again to the subjective nature of inter- 
pretations of the past and the fundamental question of whose archaeology, whose heritage, it is.

As a culturally-constructed phenomenon, heritage is not immutable. However, rather than this diminishing its potency or symbolic meaning and its emotive connection to people in the present, this is surely its strength, because it can maintain more than one version of what went before. It means that heritage discourses can sustain more than one dialogue with the past, that it can support more than one interpretation and that there is space within heritage for alternative maritime archaeologies.

\section{Conclusions}

'In the final analysis, the significance of archaeology may lie less in any specific insights gained about the past than in the very process of engaging with the material remains of the past in the present' (Holtorf, 2005: 540).

This paper has touched on and advocated some ideas which are not necessarily easily digestible or emotionally palatable to all. However, it is hoped that at the very least it will initiate further discussion of the responsibilities and personal ethics of maritime archaeologists (professional or non-professional), and the political and social implications of the practice of maritime archaeology and the production of heritage.

I am not arguing for an archaeological freefor-all, for self-motivated acquisition of the material remains of the past, but for inclusive approaches. Similarly, it is not professional standards I am arguing against, but the failure to examine the implications of professionalisation. In our rush to develop systems and policy in the face of development, and government and industry driven imperatives, we should not marginalize those outside that system, or cut out alternative engagements with the past. None of the terms and concepts we use so easily every day within heritage discussions exists within a vacuum; they are not abstract realities, universal truths, but socio-cultural constructs. There is a need for maritime archaeological heritage issues to be debated intelligently and openly, and for these assumptions to be examined rather than blindly incorporated into developing heritagemanagement systems within the UK or elsewhere. Thus the most important conclusion of this paper is the need for further reflexive examination of our approaches and for rigorously-reasoned debate, for further academic engagement and inclusive research.

The ideas drawn on here, particularly the question of 'whose archaeology it is', are part of much larger debates in archaeology. These are ideas being discussed by others in the face of Anglo-American academic archaeological dominance, in the context of the repatriation of cultural artefacts by influential museums and institutes, in light of the Iraq war, and the increasing willingness of archaeologists to serve whatever system is ascendant in order to, above all else, preserve the archaeological record (see Hamilakis, 2003; Glass, 2004; Hamilakis, 2005). We have the opportunity to engage with these ideas now and to take a leading part in these discussions, since we are uniquely placed, at a time of change and development within our part of archaeology.

We are in a remarkable position to write our own agenda. As a result, debate, discussion and academic engagement with developing our heritagemanagement ethos and policy is vital, along with some self-critical, reflexive analysis of the notions upon which we are formulating that system.

\section{Acknowledgements}

This article grew from a paper presented at the 2005 Land and Sea: Integrated Archaeologies conference. It was a personal response to several papers by Yannis Hamilakis and was intended to be reflective. However, it proved more provocative than expected, and I am grateful for comments from Jorge Manuel Herrera and Charlotte Andrews, which provided me with impetus to review my ideas. I am also grateful to Kevin Camidge, Hannah Cobb, Dave Parham, Mick Palmer and Lucy Blue for comment on this subsequent version of the paper; and finally, to Ian Oxley for his encouragement and for originally suggesting I go and say exactly what I thought.

\section{Bibliography}

Andrews, C., forthcoming, Tricky Listening: Museological inclusion of archaeologically alternative identities relating to Bermuda's underwater cultural heritage, in Conference Committee (eds) Material Culture, Identities and Social Inclusion, Conference Proceedings, University of Leicester. 
Camidge, K., 2003, HMS Colossus: Stabilisation Trail Project Design. Unpublished Report for English Heritage, http:// www.cismas.org.uk/download.htm.

Camidge, K., 2005, HMS Colossus: Stabilisation Trail Final Report. Unpublished report for English Heritage, http:// www.cismas.org.uk/download.htm.

Carman, J., 2005, Against Cultural Property: Archaeology, Heritage and Ownership. London.

DCMS, 2005, Protecting our Marine Historic Environment: Analysis of Responses. Web-published report, http://www.culture.gov.uk/ historic_environment/heritage_protection_review/

Diaz-Andreu, M. and Champion, T. (eds), 1996, Nationalism and Archaeology in Europe. London.

Dowson, T. A., 2001, Queer theory and feminist theory: towards a sociology of sexual politics in rock art research, in K. Helskog (ed.), Theoretical Perspectives in Rock Art Research, 312-29. Oslo.

Duke, P. and Saitta, D. J., 1998, An Emancipatory Archaeology for the Working Class, assemblage 4, http://www.shef.ac.uk/ assem/4/4duk_sai.html

During, E., 1994, De dog på Vasa: skelettfynden och vad de berättar. Stockholm.

Edson, G., 2004, Heritage: Pride or Passion, Product or Service?, International Journal of Heritage Studies 10.4: 333 -48.

Evans, J., 1999, Representing the nation: histories, heritage and museums. London.

Fawcett, C. and Kohl, P. L. (eds), 1995, Nationalism, Politics, and the Practice of Archaeology. Cambridge.

Friends of the Newport Ship website, http://www.newportship.com/

Gadamer, H. J., 1975, Truth and Method. London.

Glass, A., 2004, Return to Sender: On the Politics of Cultural Property and the Proper Address of Art, Journal of Material Culture 9.2, 115-39.

Hamilakis, Y., 1999, La trahision des archéologues? Archaeological Practice as Intellectual Activity in Post-Modernity, Journal of Mediterranean Archaeology 12.1, 60-79.

Hamilakis, Y., 2001, Archaeology and the burden of responsibility, in M. Pluciennik (ed.), The Responsibilities of Archaeologists: Archaeology and Ethics, 91-6. BAR Int. Ser. 981, Oxford.

Hamilakis, Y., 2002, 'The Other Parthenon': Antiquity and national memory at Markronison, Journal of Modern Greek Studies 20, 307-38.

Hamilakis, Y., 2003, Iraq, stewardship and 'the record': An ethical crisis for archaeology, Public Archaeology 3, $104-11$.

Hamilakis, Y., 2005, 'Whose world and Whose Archaeology?' The Colonial Present and the Return of the Political, Archaeologies 1.2, 94-101.

Hancock, G., 2002, Underworld: The Mysterious Origins of Civilization. London.

Harris, R., 1988, Language, Saussure and Wittgenstein: how to play games with words. London.

Holtorf, C., 2000, Engaging with multiple pasts: Reply to Francis McManamon, Public Archaeology 1, $214-15$.

Holtorf, C., 2005, Beyond crusades: how (not) to engage with alternative archaeologies, World Archaeology 37.4: 544-51.

Johnson, M., 1999, Archaeological Theory: An Introduction. Oxford.

Keys, D., 2004, 'Trading with the enemy: Tudor ship provides clues to Anglo-Spanish ties', The Independent, 18 November 2004.

McLucas, C., 2001, Dear Yannis: A letter to an archaeologist or 'From one Cultural Producer to another', in M. Pluciennik (ed.), The Responsibilities of Archaeologists: Archaeology and Ethics, 75-82. BAR Int. Ser. 981, Oxford.

McManamon, F., 2000, Archaeological messages and messengers, Public Archaeology 1, 5-20.

Marsden, P., 2003, Sealed by time: the loss and recovery of the Mary Rose. Portsmouth.

Merriman, N., 1991, Beyond the Glass Case: the public, museums and heritage in Britain. London.

Meskell, L., 1998, Archaeology under Fire: Nationalism, Politics and Heritage in the Eastern Mediterranean and Middle East. London.

Palma, P., 2005, Monitoring of Shipwreck Sites, IJNA 34.2: 323-31.

Port of London Authority, 2004, 'Remains of Elizabethan wreck found in Thames Estuary'. Press Release, 17 November.

Ransley, J., 2005, Boats are for Boys: queering maritime archaeology, World Archaeology 37.4, 621-9.

Robbins, B., 1993, Secular Vocations: Intellectuals, Professionals, Culture. London.

Roberts, O. T. P., 2004, Llong Casenewydd: the Newport Ship —a Personal View, IJNA 33.1, 158-63.

Schadla-Hall, T., 2004, The comforts of unreason: the importance and relevance of alternative archaeology, in N. Merriman (ed.), Public Archaeology, 255-71. London.

Schofield, J. and Anderton, M., 2000, The queer archaeology of Green Gate: interpreting contested space at Greenham Common Airbase, World Archaeology 32.2, 236-51.

Shanks, M. and Tilley, C., 1987, Social Theory and Archaeology. Oxford.

Skeates, R., 2002, Debating the Archaeological Heritage. London.

Smith, L., 2004, Archaeological Theory and the Politics of Cultural Heritage. London.

Stebbins, R. A., 1992, Amateurs, Professionals and Serious Leisure. Montreal and Kingston.

Taylor, B., 1995, Amateurs, professionals and the knowledge of archaeology, British Journal of Sociology 46.3, $499-508$.

Thomas, J., 1996, Time, Culture \& Identity and interpretive archaeology. London.

Thomas, J., 2004, Archaeology and Modernity. London.

Tilley, C., 1989, Excavation as Theatre, Antiquity 63, 275-80.

Trigger, B. G., 1989, A History of Archaeological Thought. Cambridge.

Wallis, R. J., 2003, Shamans/neo-shamans: ecstasy, alternative archaeologies, and contemporary pagans. London.

Wallis, R. J. and Lymer, K. (eds), 2001, A Permeability of Boundaries: New Approaches of Art, Religion and Folklore. BAR Int. Ser. 936, Oxford. 
Wittgenstein, L., 1958, Philosophical Investigations. Oxford.

Wylie, A., 1996, Ethical dilemmas in archaeological practice: Looting, repatriation, stewardship, and the (trans)formation of disciplinary identity, Perspectives on Science 4, 154-94.

Wylie, A., 2005, The Promise and Perils of an Ethic of Stewardship, in L. Meskell and P. Pels (eds), Embedding Ethics, 47-68. Oxford and New York.

Zimmerman, L. J., 1995, Regaining our nerve: Ethics, values, and the transformation of archaeology, in M. J. Lynott and A. Wylie (eds), Ethics in American Archaeology: Challenges for the 1990s, 64-7. Washington DC. 